\title{
QUEEN'S
UNIVERSITY
BELFAST
}

\section{Large strain, high rate semi-solid deformation of High Density Polyethylene at elevated temperatures}

McKelvey, D., Menary, G., Martin, P., \& Yan, S. (2017). Large strain, high rate semi-solid deformation of High Density Polyethylene at elevated temperatures. Polymer Engineering and Science.

https://doi.org/10.1002/pen.24723

\section{Published in:}

Polymer Engineering and Science

\section{Document Version:}

Peer reviewed version

Queen's University Belfast - Research Portal:

Link to publication record in Queen's University Belfast Research Portal

Publisher rights

(c) 2017 Wiley This work is made available online in accordance with the publisher's policies. Please refer to any applicable terms of use of the publisher.

\section{General rights}

Copyright for the publications made accessible via the Queen's University Belfast Research Portal is retained by the author(s) and / or other copyright owners and it is a condition of accessing these publications that users recognise and abide by the legal requirements associated with these rights.

Take down policy

The Research Portal is Queen's institutional repository that provides access to Queen's research output. Every effort has been made to ensure that content in the Research Portal does not infringe any person's rights, or applicable UK laws. If you discover content in the Research Portal that you believe breaches copyright or violates any law, please contact openaccess@qub.ac.uk. 
Large strain, high rate semi-solid deformation of High Density

\section{Polyethylene at elevated temperatures}

D. McKelvey ${ }^{1}$, G.H. Menary ${ }^{1}$, P.J. Martin ${ }^{1}$ and S. Yan ${ }^{1}$

1. School of Mechanical and Aerospace Engineering, Queen's University of Belfast, BT9 5AH, Belfast, Northern Ireland, U.K 


\section{Abstract}

High density polyethylene (HDPE) is predominately processed from the molten state. However, there is the potential to enhance the mechanical properties by forming below the melt temperature, in the semi-solid phase. To further investigate this enhancement, HDPE sheets were deformed under constant width (CW), simultaneous equal biaxial (EB) and sequential biaxial (SQ) deformation. The samples were deformed at strain-rates, from $4 \mathrm{~s}^{-1}$ to $16 \mathrm{~s}^{-1}$, up to nominal strains of 3.0 at temperatures below $130^{\circ} \mathrm{C}$. The strain-rate and high-strain level applied were chosen so that the data was comparable to the thermoforming process. It was discovered that in order for the HDPE sheet to deform at the highrate and high strains the processing temperature must be between $126^{\circ} \mathrm{C}$ and $130^{\circ} \mathrm{C}$. This resulted in a processing window that was particularly small, $5^{\circ} \mathrm{C}$, and that within this window a temperature change of $1^{\circ} \mathrm{C}$ had a significant impact on the stress-strain response. The samples were analyzed post deformation, where the elastic modulus was found to increase by a factor of 2.08 in the MD, when deformed via EB at $129^{\circ} \mathrm{C}$. The results showed that HDPE can be deformed to strain levels comparable to the thermoforming process. 


\section{Introduction}

High density polyethylene (HDPE) is the polymer of choice for many applications, such as milk bottles, oil tanks, chemical containers, grocery bags and packaging film. HDPE is predominately processed in the molten state via injection, extrusion and extrusion blow molding, where the polymer melt is manipulated into the desired shape. However, processing HDPE in the semi-solid phase, by processes such as thermoforming, has never reached the same levels of industrial success as melt processing and in fact HDPE is rarely thermoformed. A few studies [1,2] have shown that extruding HDPE just below the melting temperature in the semi-solid state, can significantly improve the mechanical properties when compared to extrusion from the molten state. For example, Li et al. [1] found that the yield strength of extruded HDPE could be improved from 28MPa when processed from the molten state to $181 \mathrm{MPa}$ when extruded below the melting temperature. Therefore, there are potentially some clear benefits to forming HDPE in the semi-solid phase but as yet, there has been no published studies focusing on the mechanical response under comparable conditions.

In order to successfully form a material, the materials response within the processing range must be fully understood so that the processing parameters can be optimized to produce a high quality product. The thermoforming process involves a range of biaxial deformation, including constant width (CW), simultaneous equal-biaxial (EB) and sequential biaxial (SQ) deformation at strain-rates in the range of 0.1-10 s ${ }^{-1}$ and higher, for PP, HIPS and ABS [3]. However, there was no comparable study found within the literature that outlines the processing range for HDPE. As HDPE is a member of the polyolefin family, like PP, comparisons from previous work can be drawn for instance, Capt et al. [4] and Martin et al. [5] investigated PP at temperatures approaching the melting temperature under CW, EB and SQ deformation at strain-rates up to $1.5 \mathrm{~s}^{-1}$ and $32 \mathrm{~s}^{-1}$ respectively. Most studies investigating HDPE at elevated temperatures have focused on the corresponding changes in the microstructure. While investigating the effect of HDPE/MWCNT nanocomposites, Dong et al. [6] showed the stress-strain response for neat HDPE during EB deformation at $131^{\circ} \mathrm{C}$ and $4 \mathrm{~s}^{-1}$. The stress-strain response showed a fairly well defined yield point followed by no significant strain-hardening. Furthermore, Hillmansen and Hobeika [7] investigated the stress-strain behavior of HDPE under uniaxial deformation at temperatures ranging from room temperature to just below the melting temperature. One of the key findings from this study was that the strain-hardening behavior for uniaxial deformation is dependent on the deformation temperature, where increasing the temperature reduces the hardening. They observed no significant 
strain hardening at higher temperatures, $128^{\circ} \mathrm{C}$, which was comparable with Dong et al. [6]. They proposed that the results were due to entanglements linking the crystalline regions. In HDPE these are present due to the crystalline structure and as the crystalline content decreases with increasing temperature so does the anchor points linking the entanglements and hence, the lack of strainhardening. Additionally, they indicate the temperature-dependence of the yield, with the yield point becoming less pronounced as the temperature increases. With regards to the microstructure of HDPE, serval studies have investigated the change in the microstructure during uniaxial deformation at temperatures ranging from $100^{\circ} \mathrm{C}$ to $135^{\circ} \mathrm{C}$, using a combination of synchrotron WAXS and SAXS [812]. A key finding was that the uniformity of deformation increased with increasing deformation temperature [8] and that the microstructure was significantly modified during the heating stage [9]. The enhanced uniformity with increasing temperature is not surprising given the ability of HDPE to reorganize and for crystal perfection to increase [13] at elevated temperatures below the melting temperature. The enhanced crystal perfection reduces the lamellae thickness distribution leading to more uniform deformation [14]. The majority of the work published on HDPE has been based on uniaxial deformation however, this is not representative of industrial processes such as thermoforming or film stretching. Meng et al. [11] compared uniaxial deformation and CW deformation for HDPE with a key finding that for stretch ratios below 3.5 the samples had different microstructures, resulting from the boundary conditions applied. This highlights a significant limitation in using uniaxial data alone and hence, to achieve a representative mechanical response, comparable deformation modes should be applied. The response of HDPE typically exhibits a strain-rate dependence, at low strain rates such as $0.001-0.00001 \mathrm{~s}^{-1}[15]$ and $0.1-0.001 \mathrm{~s}^{-1}[16]$ under uniaxial deformation, at room temperature. However, these rates are significantly slower when compared with rates experienced in thermoforming [3] and hence, are not directly relevant. Additionally, the strain-rate dependence has been shown to decrease with increasing temperature for HDPE [17] and hence, there is a need to understand the effect of the strain-rate at elevated temperatures.

Therefore, while there is potential to enhance the mechanical properties by processing in the semi-solid state, there is currently a lack of understanding in regard to the processing window along with property enhancement. The aim of this study was to investigate the large strain formability of HDPE in the semisolid phase. The objectives were to firstly identify the forming window. Secondly, to investigate the 
materials response under large strain, at strain-rates typical of the thermoforming process [5] .Thirdly, to analyze the effect of the forming on the mechanical properties post deformation.

\section{Materials and Methods}

\subsection{Sample Preparation}

The HDPE resin used in this study had a Mn of $28.6 \mathrm{kDa}$, Mw of $151.2 \mathrm{kDa}$ and Mz of $850.2 \mathrm{kDa}$. HDPE samples with dimensions $76 \times 76$ × 2mm were injection molded using an Arburg 320 S Allrounder 500350 machine. The injection temperature was $235^{\circ} \mathrm{C}$ and the injection pressure was $85 \mathrm{MPa}$, samples were held in the mold at $30^{\circ} \mathrm{C}$ for 15 seconds, before ejection.

\subsection{Dynamic Mechanical Analysis (DMA)}

DMA was conducted using a Triton Tritec 2000 DMA. Specimens of dimensions $25 \times 7.75 \times 1.85 \mathrm{~mm}$ were loaded in dual cantilever configuration with a span length of $15 \mathrm{~mm}$. Temperature sweeps at constant frequency of $1 \mathrm{~Hz}$ and displacement of $0.025 \mathrm{~mm}$ were conducted between $35^{\circ} \mathrm{C}$ and $135^{\circ} \mathrm{C}$ at a rate of $1^{\circ} \mathrm{C} / \mathrm{min}$.

\subsection{Differential Scanning Calorimetry (DSC)}

A Perkin Elmer DSC6 was used to analyze $10 \mathrm{mg}$ samples of HDPE, cut from the injection-molded sheet. The samples were heated to $180^{\circ} \mathrm{C}$ and held for 3 minutes, to ensure the sample was completely melted, and then cooled to room temperature. The crystallinity was determined by dividing the area under the endotherm by the enthalpy of fusion for PE, which was taken as $293 \mathrm{~J} / \mathrm{g}$ [18]. The experiment was repeated three times and an average was taken for the degree of crystallinity and peak crystalline melting temperature.

\subsection{Forming Experiments}

The Queen's University of Belfast (QUB) biaxial stretcher was used to replicate forming conditions for HDPE, as previously used for PP, HIPS and PET $[5,19]$. The equilibrium heating time was determined by comparing the stress-strain response for different heating times of 2, 4 and 8 minutes. The results showed that there was no change in the response between 4 and 8 minutes and hence, a heating time of 4 minutes was determined to be the equilibrium time. The heating time was further validated by simulating the heating procedure in the commercial finite element package Abaqus, where temperature dependent thermal conductivity, ranging from $0.2-0.5 \mathrm{~W} / \mathrm{m} . \mathrm{K}$, and specific heat capacity, ranging from 
1944-18663 J/KgK were applied [20]. The simulation predicted that after 4 minutes the variation was less than $0.5^{\circ} \mathrm{C}$. Hence, a heating time of 4 minutes was applied for all tests. In this study constant width $(\mathrm{CW})$, simultaneous equal-biaxial $(\mathrm{EB})$ and sequential biaxial $(\mathrm{SQ})$ deformation modes were applied to simulate industrial forming conditions at nominal strain rates of 4,8 and $16 \mathrm{~s}^{-1}$. The deformation modes are shown in Figure 1. All stress strain curves displayed are the average curves determined from 3 tests, carried out on 3 consecutive days. Additionally, sample orientation was controlled throughout all the tests, where the machine direction (MD) referred to flow direction from injection and the transverse direction (TD) referred perpendicular to the MD.

\subsection{Tensile Testing}

Dog-bone specimens were cut from biaxially stretched HDPE sheets and analyzed post-deformation at room temperature, in both the MD and TD in accordance with ISO 527-2:2012(E) - Type 1BA, using an Instron 5564. The modulus was determined from nominal strain range of 0.05 to $0.25 \%$ and an average value was determined from 4 repeats. The gauge length was $55 \mathrm{~mm}$ and the deformation rate was $1 \mathrm{~mm} / \mathrm{min}$.

\section{Results}

\subsection{DMA}

The storage modulus and the loss modulus results are shown in Figure 2 as a function of temperature. The storage modulus was initially $4 \mathrm{kPa}$ at $35^{\circ} \mathrm{C}$ and then decreased almost linearly until the temperature reached $60^{\circ} \mathrm{C}$. The storage modulus continued to decrease after this but, with a change in the gradient of the storage modulus. Furthermore, the storage modulus decreased by $75 \%$, within $50^{\circ} \mathrm{C}$, to $1 \mathrm{kPa}$ at $85^{\circ} \mathrm{C}$ and continued to decrease further, until it reached approximately $0.015 \mathrm{kPa}$ at $135^{\circ} \mathrm{C}$. The loss modulus was initially $530 \mathrm{~Pa}$ at $35^{\circ} \mathrm{C}$ and remained constant until $50^{\circ} \mathrm{C}$, after which it began to decrease fairly linearly to $260 \mathrm{~Pa}$ at $85^{\circ} \mathrm{C}$ and then continued to decrease to $30 \mathrm{~Pa}$ and $135^{\circ} \mathrm{C}$. The corresponding tan delta (ratio of loss modulus to storage modulus) curve is shown in Figure 2. The initial tan delta was 0.13 at $35^{\circ} \mathrm{C}$, it then increased linearly to 0.2 at $60^{\circ} \mathrm{C}$ and then continued to increase at a lower rate to 0.35 at $125^{\circ} \mathrm{C}$ after which, it increased dramatically to 0.45 at $133^{\circ} \mathrm{C}$ before beginning to decrease. Thus, indicating a peak in the tan delta curve commencing at $125^{\circ} \mathrm{C}$, indicating a potential forming temperature. 


\subsection{DSC}

The heat flow against temperature plot obtained from DSC is shown in Figure 3. Firstly analyzing the melting peak, a melting range was observed due to a distribution of crystal sizes as commonly observed in semi-crystalline polymers, with smaller crystals melting first. The first sign of melting occurs at approximately $95^{\circ} \mathrm{C}$ with the onset of bulk melting commencing at $121^{\circ} \mathrm{C}$ and a peak melting temperature of $131^{\circ} \mathrm{C}$. The area under the melting peak equated to a change in enthalpy of $198 \mathrm{~J} / \mathrm{g}$, which resulted in a crystallinity of $68 \%$. Secondly, analyzing the cooling peak the first evidence of crystallization occurs at $116^{\circ} \mathrm{C}$, with the peak crystallization occurring at $112^{\circ} \mathrm{C}$.

\subsection{Forming Conditions}

The initial temperature range considered for biaxial tests was been $125-133^{\circ} \mathrm{C}$, based on the peak observed from DMA results in Figure 2. For the strain-rates applied in this study it was found that samples could not be deformed below $125^{\circ} \mathrm{C}$, the sample was too stiff and was pulled from the grips with minimal deformation. For temperatures above $130^{\circ} \mathrm{C}$, the sample did not have sufficient structural integrity and hence, could not be successfully deformed. Therefore, the temperature processing window was defined as $126^{\circ} \mathrm{C}$ to $130^{\circ} \mathrm{C}$, for the grade of HDPE used in this study. The stress-strain response during EB deformation is shown in Figure 4 for nominal strains up to 2.0 in the $\mathrm{MD}$, for each temperature within the temperature processing window. The results indicate a clear temperature dependence with a temperature change of $1^{\circ} \mathrm{C}$ resulting in a shift in the stress response. The response at $126^{\circ} \mathrm{C}$ yields at a nominal strain of 0.3 , a slight strain softening was observed post-yield and then a gradual increase in stress with increasing nominal strain was observed. There was no strain softening observed at temperatures above $126^{\circ} \mathrm{C}$. The stress response in Figure 4 did not exhibit any significant strain hardening however, the gradient of the post-yield deformation was highest at $126^{\circ} \mathrm{C}$ and then decreased with increasing temperature. It is evident from Figure 4 that the yield stress decreased by $64 \%$ within the $5^{\circ} \mathrm{C}$ temperature processing window. Furthermore, the change in yield stress was more significant between $126^{\circ} \mathrm{C}$ and $128^{\circ} \mathrm{C}$, with approximately $50 \%$ drop, when compared with $128^{\circ} \mathrm{C}$ to $130^{\circ} \mathrm{C}$.

The typical stress-strain response is shown in Figure 5 for EB deformation. The yield stress, 1.2MPa, was the same in both directions but, a level of anisotropy was observed between the MD and the TD for larger strains. The initial sample orientation was rotated through $90^{\circ}$ and the same trend was observed, where a stiffer response was observed throughout in the MD. The effect of increasing the strain-rate is shown in Figure 5. The results show that the strain-rate has minimal effect on the stress 
response and that the yield stress was almost constant with increasing strain-rate, within the range investigated in the current study. However, interestingly the strain-rate affected the failure strain. For a strain rate of $4 \mathrm{~s}^{-1}$ the failure strain was 2.85 while this was reduced to 2.05 for a strain-rate of $8 \mathrm{~s}^{-1}$ and this was further reduced to 1.75 for strain-rate $16 \mathrm{~s}^{-1}$ for EB deformation.

The sample orientation relative to the deformation direction, during CW and SQ, is shown in Figure 6 and is key regarding the description of the results. The stress response under CW loading is shown in Figure 7, compared with EB. Firstly, the sample orientation during CW deformation was investigated. The stress response when the sample was deformed in the MD was significantly higher than the stress response in the TD. The CW_MD response was higher than the EB response in both directions but, the yield strain was the same as the CW and EB deformation modes. However, the yield stresses were not the same with CW_MD having the highest yield stress of $1.8 \mathrm{MPa}$, both directions in EB had a yield stress of $1.2 \mathrm{MPa}$ and the yield stress in $\mathrm{CW} \_\mathrm{TD}$ was $0.8 \mathrm{MPa}$. The final stress in CW_MD was roughly three times the stress in CW_TD, indicating the importance of sample orientation for CW deformation.

The sample orientation was also investigated during SQ deformation, as shown in Figure 8 where true stress is plotted against time. The same trend was observed as in CW deformation, where a higher stress response was observed when the MD was deformed first. The stress was observed to drop for both orientations when the first deformation step was completed and the second deformation step began, the stress decreased by $3 \mathrm{MPa}$ for MD first whereas, the drop for TD first was 0.5MPa. Furthermore, during the second deformation step the stress response was higher when the MD was deformed second.

\subsection{Effect of Forming on Elastic Modulus}

The initial elastic modulus was $606 \mathrm{MPa}$ in the MD and 391MPa in the TD. The modulus post deformation was shown to increase by a factor of 2.0 in the MD and 3.3 in the TD. After EB deformation at $128^{\circ} \mathrm{C}$, the level of anisotropy that was initially observed was reduced from a ratio of 1.55 to 1.08 . Furthermore, there was no temperature or strain-rate dependence observed on the modulus, as all the values fell within the experimental error as shown in Figure 9. The effect of deformation mode is shown in Figure 10, note only the modulus in the deformation direction could be measured during $\mathrm{CW}$ deformation as the samples were not wide enough to cut a dog-bone test specimen from. Post CW deformation, the modulus increased by a factor of 2.0 and 2.9 in the MD and TD respectively. A similar 
trend was observed post EB deformation, where the modulus increased by a factor of 2.1 and 3.3 in the MD and TD respectively. The sample orientation and the deformation direction was found to have a significant impact on the modulus enhancement post forming. When the TD was deformed first (SQ_TD) the modulus was further increased by a factor of 2.5 and 4.0, in the MD and TD respectively. However, when the MD was deformed first (SQ_MD) the modulus was only enhanced by a factor of 1.6 and 1.9, in the MD and TD respectively. The sample that was deformed via SQ_MD exhibited a series of stress induced crazes, after the initial $\mathrm{CW}$ deformation, in contrast to all the other processing conditions where no crazing was observed.

\section{Discussion}

The results show that HDPE can be formed in the semi-solid phase, to large strains at rates comparable with the thermoforming process. The temperature processing window was found to be between 126 and $130^{\circ} \mathrm{C}$, with the final strain level dependent upon the strain-rate applied. The use of DMA to determine the temperature processing window proved to be particularly successful, with the onset of the tan delta peak observed at $125^{\circ} \mathrm{C}$ corresponding to the lowest temperature at which biaxial deformation could be applied. This temperature range is above the alpha relaxation temperature observed, which signals the strong activation of crystal shearing which in turn causes the strained chains within the intra-lamellar amorphous phase to relax [8] [21]. Furthermore, the temperature range is within the crystalline melting range observed via DSC, commencing at $95^{\circ} \mathrm{C}$. Therefore, the onset of melting reduces the crystalline content and enables further relaxation of strained chains within the material thus, increasing the ability to deform.

The crystallinity was estimated to be $44 \%$ and $22 \%$ at $126^{\circ} \mathrm{C}$ and $130^{\circ} \mathrm{C}$ respectively, measured via DSC. This clearly indicates the temperature sensitivity of HDPE as the crystallinity was halved within a temperature change of $4^{\circ} \mathrm{C}$. However, to get an accurate measurement of the crystallinity during heating, in-situ measurements would be required. The temperature sensitivity was further underlined by the fact that a change in temperature of $1{ }^{\circ} \mathrm{C}$ results in a shift in the stress response, as shown in Figure 4. The yield stress was observed to decrease from 2.4 to $0.85 \mathrm{MPa}$ within the temperature range, which was to be expected based on the widely accepted relationship that higher crystallinity results in a higher yield stress i.e. lower crystallinity leads to a lower modulus [22-26]. Furthermore, from an industrial point of view, temperature control would be a critical aspect as poor temperature control could 
result in a highly non-uniform part being produced. While a very clear temperature sensitivity was observed in the stress-strain behavior during deformation there was no such dependence observed in the room temperature elastic modulus data post deformation, when the strain rate and level was kept constant. This corresponds with the post deformation crystallinity, which was determined to be $63 \%$ and $66 \%$ for samples deformed at 126 and $130^{\circ} \mathrm{C}$ respectively thus, indicating minimal variation. However, to gain a clear understanding of the effect of the cooling post deformation, additional cooling regimes should be studied where more rapid cooling and extended cooling periods are applied.

The level of strain hardening for PE has been attributed to the molecular weight (Mw) of the particular grade, with a higher Mw resulting in a higher strain hardening modulus. Ward [27] found that for a Mw greater than $10^{5}$ the long chain molecules are likely to be included in more than one crystalline lamellae and hence, the total number of entanglements increases resulting in an increase in the strain hardening. The lack of significant strain hardening observed at $128^{\circ} \mathrm{C}$ was consistent with the findings of Hillmansen et al [7], who explained the results by a reduction of the entanglement anchor points located within the crystalline regions, due to crystal melting. The resin used in the current study had an Mw of 151.2 kDa and hence, a similar analogy could be applied to describe the results. It should also be noted, that typically the gradient of the stress response did increase with strain however, the sharp upturn indicative of strain hardening was not observed for the strain range investigated.

The strain-rate data showed that there was no statistically significant strain-rate dependence, based on the stress response observed. This was unexpected, given the large amount of published work showing a strain-rate dependence, particularly for lower strain-rates at lower temperatures. However, the strainrates investigated in the current study were considerably higher than the majority of published work and based on the experimental error, no clear strain-rate dependence was observed. The relative strainrate independence observed at $128^{\circ} \mathrm{C}$ was comparable with the findings of Zeltmann et al. [17], who observed strain-rate dependence decreased with increasing temperature. Furthermore, Martin et al. [5] observed a similar stress response for PP deformed via EB in the semi-solid phase, at rates of 8 and $16 \mathrm{~s}^{-1}$, were no clear strain-rate dependence was observed. However, they did observe a weak strainrate dependence over the range of strain-rates investigated, from $1 \mathrm{~s}^{-1}$ to $32 \mathrm{~s}^{-1}$. Hence, a more detailed study investigating the strain-rate dependence over a wider strain-rate and temperature range would be required to fully investigate the relationship. The failure strain was observed to depend on the strainrate, with the failure strain reducing from 2.75 to 1.8 , by increasing the strain-rate from $4 \mathrm{~s}^{-1}$ to $16 \mathrm{~s}^{-1}$. 
Furthermore, considering the elastic modulus post deformation was not affected by the deformation strain-rate, it would be advantageous to process at $4 \mathrm{~s}^{-1}$ compared to $16 \mathrm{~s}^{-1}$ due to the higher strain levels that can be applied.

The deformation mode was observed to have a significant impact on the stress-strain response and in particular during $\mathrm{CW}$ deformation, where the sample orientation significantly altered the stress-strain response. The highest stress response was observed when the sample was deformed in the MD via $\mathrm{CW}$, even higher than the response observed during EB. This was potentially a result of the initial crystalline orientation, which was orientated preferentially in the deformation direction, resulting in a higher stress response. The deformation in the TD produced the lowest stress response, clearly indicating the importance of the sample orientation. Butler and Donald [28] showed a similar trend for blown film, where the preferred orientation resulted in a stiffer response. They accounted for the differences in the sample orientations with lamellae corrugating in the MD whereas, lamellae thinning and intra-lamellar shear occurred in the TD and $45^{\circ}$ respectively. The same trend was observed during SQ deformation in this study where, the highest stress-strain response was observed in the MD.

The modulus was significantly affected by the sample orientation during both CW and SQ deformation. The higher modulus obtained in the MD during $\mathrm{CW}$ follows the trend observed previously but, the modulus post SQ deformation was found to be highly dependent on the sample orientation. When the first deformation was in the TD, the modulus increased by a factor of 2.5 and 4.0 , in the MD and TD respectively. Whereas, when the deformation was in the MD first, the modulus increased by a factor of 1.6 and 1.9 , in the MD and TD respectively. Therefore, by simply changing the initial sample orientation relative to the deformation direction the modulus enhancement ratio was reduced by 0.9 in the MD and 2.1 in the TD. However, when the SQ deformation was firstly in the MD a series of crazes were observed after the second stretch. This phenomenon was not observed when the sample was deformed in the TD first. To fully understand the relationship between the deformation and the modulus a more detailed study would be required where strain level and deformation mode should be analyzed, ideally with the corresponding microstructural changes.

\section{Conclusions}

The current study showed that like polypropylene [5], HDPE in the semi-solid phase can be deformed to large strains at rates comparable with the thermoforming process. The temperature processing 
window was determined to be particularly small, between 126 and $130^{\circ} \mathrm{C}$, and within the window, a temperature change of $1^{\circ} \mathrm{C}$ was significant to shift the stress response. The data showed no statistically significant strain-rate dependence, within the range investigated. Additionally, the sample orientation relative to the deformation direction was found to significantly impact both the stress response and the elastic modulus post deformation. The elastic modulus post deformation was found to increase as a result of the deformation applied. The most significant enhancement was observed after SQ deformation with the initial deformation step in the TD and the least significant enhancement was observed after $S Q$ deformation with the initial deformation step in the MD. Therefore, the elastic modulus can be enhanced by forming and hence, thinner parts can be produced without reducing the mechanical performance. Further work is required to determine the relationship between the deformation and the elastic modulus, to establish the optimal processing conditions, along with a series of thermoforming trials to fully validate the results.

\section{References}

1. Li Y, Chen J, Yuan Y, Shen K, Guo J. Study on Properties and Structure of Near Melt Point Extruded High-Density Polyethylene. J Macromol Sci Part B. 2008;47(3):426-33.

2. Zheng H, Wang B, Zheng G, Wang Z, Dai K, Liu C, et al. Study on Crystallization Kinetics of Partially Melting Polyethylene Aiming To Improve Mechanical Properties. Ind Eng Chem Res. 2014 Apr 9;53(14):6211-20.

3. Bourgin P, Cormeau I, Saint-Matin T. A first step towards the modelling of the thermoforming of plastic sheets. J Mater Process Tech. 1995;54(1-4):1-11.

4. Capt L, Rettenberger S, Münstedt H, Kamal MR. Simultaneous biaxial deformation behavior of isotactic polypropylene films. Polym Eng Sci. 2003;43(7):1428-41.

5. Martin PJ, Tan CW, Tshai KY, McCool R, Menary G, Armstrong CG, et al. Biaxial characterisation of materials for thermoforming and blow moulding. Plast Rubber Compos. 2005;34(5-6):276-82.

6. Xiang D, Harkin-Jones E, Linton D. Processability, structural evolution and properties of melt processed biaxially stretched HDPE/MWCNT nanocomposites. RSC Adv. 2014;4(83):44130- 
40.

7. Hillmansen S, Hobeika S. The effect of strain rate, temperature, and molecular mass on the tensile deformation of polyethylene. Polym Eng Sci. 2000;40(2):481-9.

8. Xiong B, Lame O, Chenal JM, Rochas C, Seguela R, Vigier G. Amorphous phase modulus and micro-macro scale relationship in polyethylene via in situ SAXS and WAXS.

Macromolecules. 2015;48(7):2149-60.

9. Jiang Z, Tang Y, Rieger J, Enderle HF, Lilge D, Roth S V., et al. Structural evolution of tensile deformed high-density polyethylene at elevated temperatures: Scanning synchrotron smalland wide-angle X-ray scattering studies. Polymer. 2009;50(16):4101-11.

10. Tian Y, Zhu C, Gong J, Yang S, Ma J, Xu J. Lamellae break induced formation of shish-kebab during hot stretching of ultra-high molecular weight polyethylene precursor fibers investigated by in situ small angle X-ray scattering. Polym (United Kingdom). 2014;55(16):4299-306.

11. Meng L, Xu J, Chen X, Tian N, Lin Y, Cui K, et al. Constrained and free uniaxial stretching induced crystallization of polyethylene film: A comparative study. Polym Test. 2014;36:110-8.

12. Jiang Z, Tang Y, Rieger J, Enderle HF, Lilge D, Roth S V., et al. Structural evolution of meltdrawn transparent high-density polyethylene during heating and annealing: Synchrotron smallangle X-ray scattering study. Eur Polym J. 2010;46(9):1866-77.

13. Xu RJ, Chen XD, Cai Q, Chen CB, Lin YF, Lei CH, et al. In situ study of the annealing process of a polyethylene cast film with a row-nucleated crystalline structure by SAXS. RSC Adv. 2015;5(35):27722-34.

14. Hosoda S, Nozue Y, Kawashima Y, Utsumi S, Nagamatsu T, Wagener K, et al. Perfectly controlled lamella thickness and thickness distribution: A morphological study on ADMET polyolefins. Macromol Symp. 2009;282(1):50-64.

15. Dusunceli N, Colak OU. The effects of manufacturing techniques on viscoelastic and viscoplastic behavior of high density polyethylene (HDPE). Mater Des. 2008;29(6):1117-24.

16. Hobeika S, Men Y, Strobl G. Temperature and Strain Rate Independence of Critical Strains in Polyethylene and Poly(ethylene- c o -vinyl acetate). Macromolecules. 2000;33:1827-33. 
17. Zeltmann SE, Bharath Kumar BR, Doddamani M, Gupta N. Prediction of strain rate sensitivity of high density polyethylene using integral transform of dynamic mechanical analysis data. Polymer. 2016;101:1-6.

18. Wunderlich B. Crystal structure morphology, defects. Macromol Phys. 1973;1(Academic Press).

19. Menary GH, Tan CW, Harkin-Jones EMA, Armstrong CG, Martin PJ. Biaxial Deformation and Experimental Study of PET at Conditions Applicable to Stretch Blow Molding. Polym Eng Sci. 2012;52:671-88.

20. Boztepe S, Thiam A, Almeida O De, Maoult Y Le, Schmidt F. Experimental analysis on the coupled effect between thermo- optical properties and microstructure of semi-crystalline thermoplastics. In: 19th International ESAFORM Conference on Material Forming Nineteenth International ESAFORM Conference on Material Forming International ESAFORM Conference on Material Forming. 2016.

21. Xiong B, Lame O, Chenal JM, Rochas C, Seguela R, Vigier G. Temperature-Microstructure Mapping of the Initiation of the Plastic Deformation Processes in Polyethylene via In Situ WAXS and SAXS. Macromolecules. 2015;48(15):5267-75.

22. Sirotkin RO, Brooks NW. The effects of morphology on the yield behaviour of polyethylene copolymers. Polymer. 2001;42(8):3791-7.

23. Brooks NWJ, Mukhtar M. Temperature and stem length dependence of the yield stress of polyethylene. Polymer. 2000;41(4):1475-80.

24. Humbert S, Lame O, Vigier G. Polyethylene yielding behaviour: What is behind the correlation between yield stress and crystallinity? Polymer. 2009;50(15):3755-61.

25. Humbert S, Lame O, Segula R, Vigier G. A re-examination of the elastic modulus dependence on crystallinity in semi-crystalline polymers. Polymer. 2011;52(21):4899-909.

26. Kennedy M a., Peacock a. J, Mandelkern L. Tensile properties of crystalline polymers: Linear polyethylene. Macromolecules. 1994;27(19):5297-310.

27. Ward IM. The role of molecular networks and thermally activated processes in the deformation 
behavior of polymers. Polym Eng Sci.

1984 Jul 1;24(10):724-36.

28. Butler M, Donald A. Real-time in situ light scattering and X-ray scattering studies of polyethylene blown film deformation. J Appl Polym Sci. 1998;(Md):321-39.
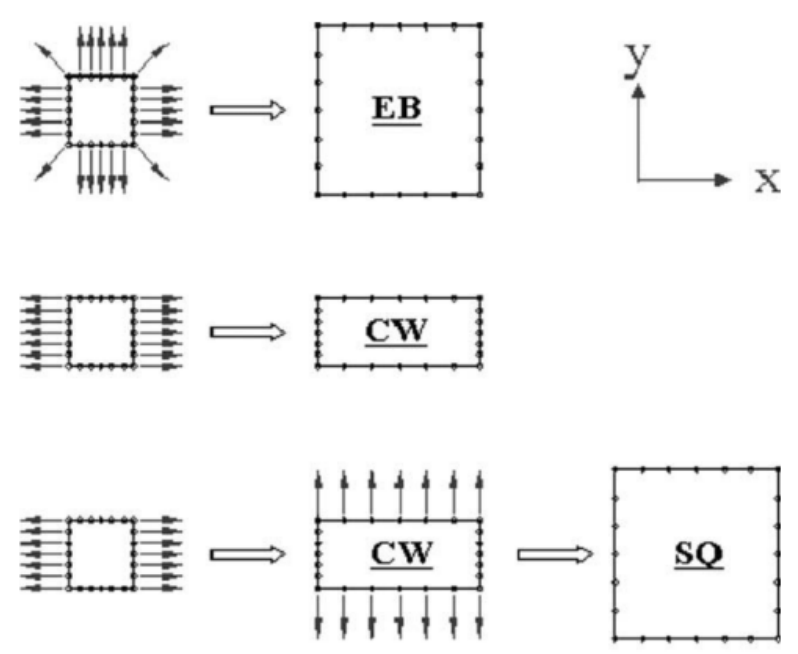

Figure 1- Deformation modes applied

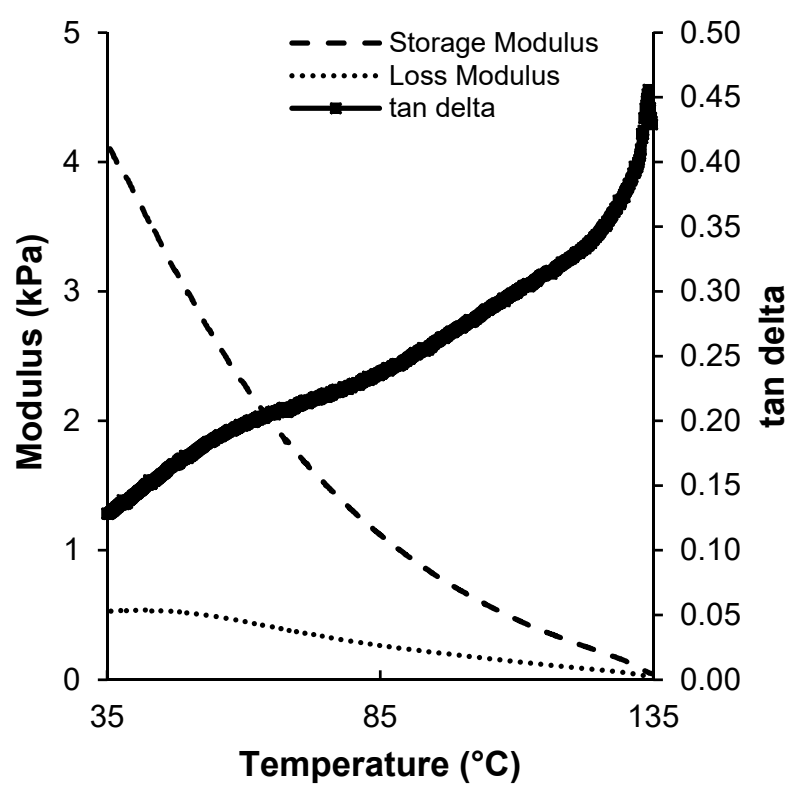

Figure 2 - DMA temperature sweep 


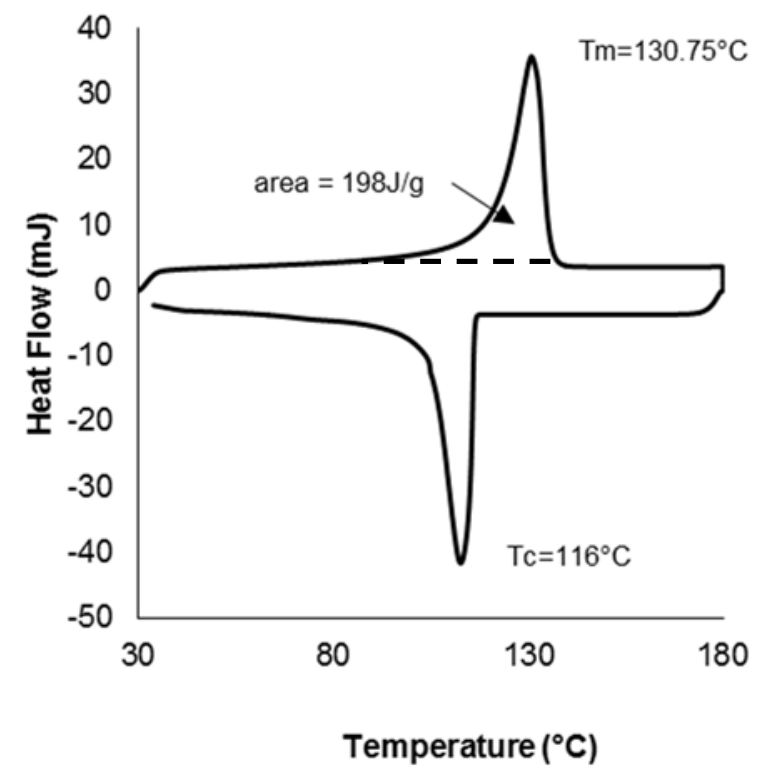

Figure 3 - DSC curves obtained from the initial sample, endo up

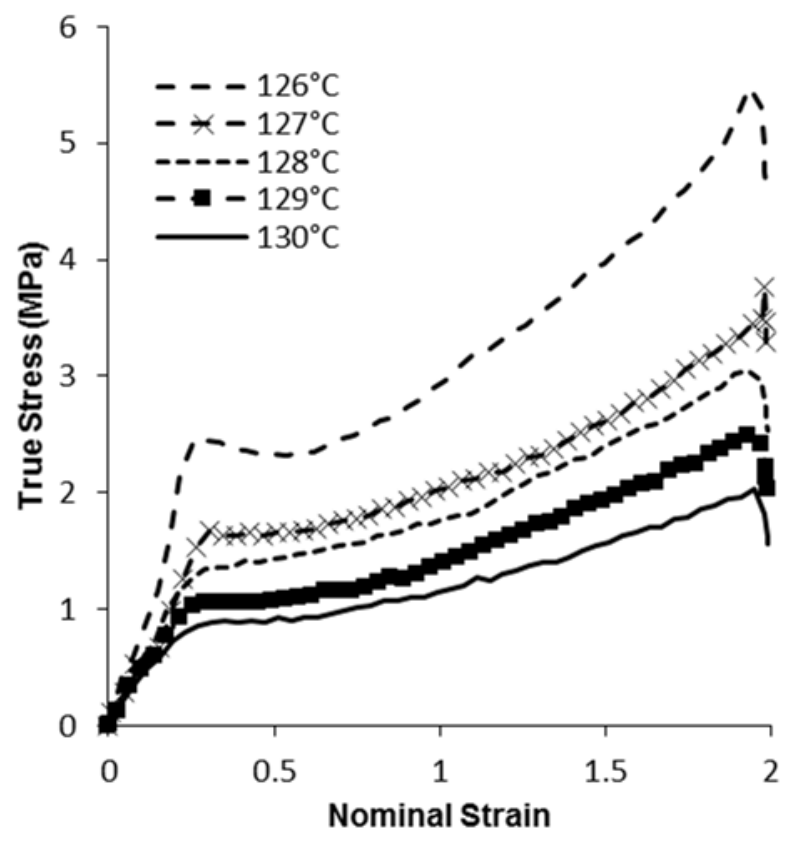

Figure 4 - Temperature dependence observed during EB deformation in the MD at a strain-rate of $4 \mathrm{~s}^{-1}$ 
(A)

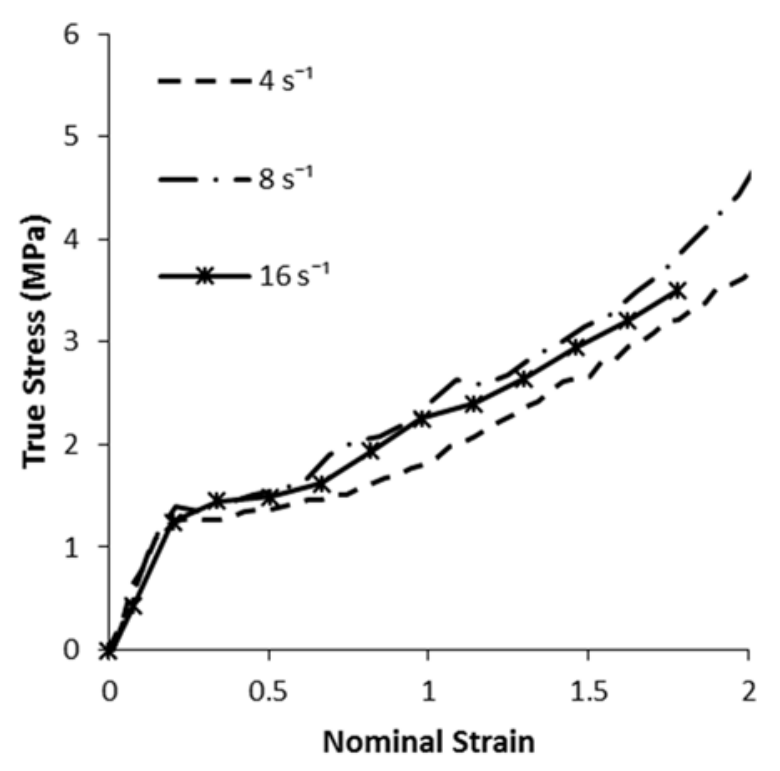

(B)

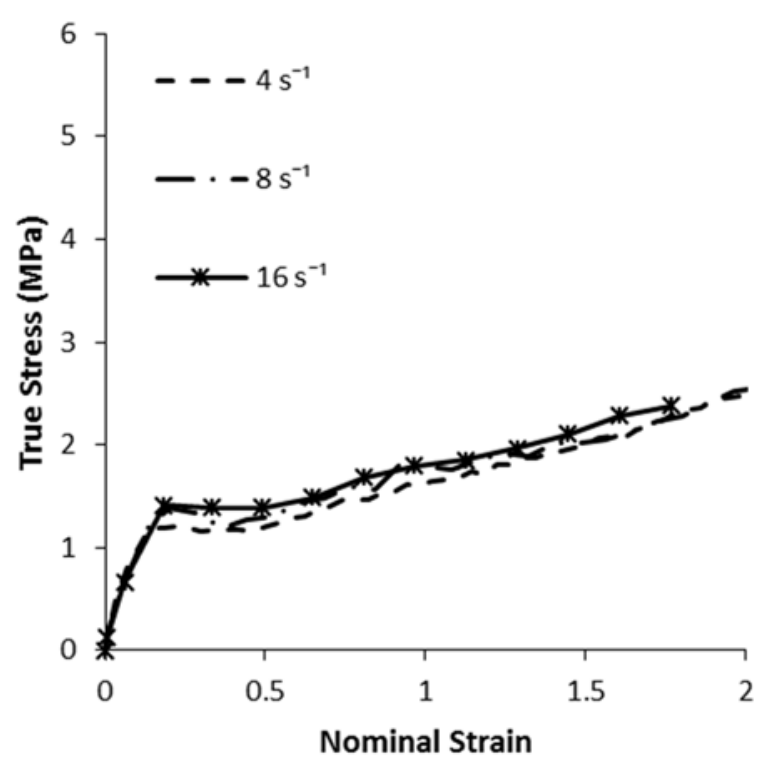

Figure 5 - Strain-rate dependence observed during EB deformation at $128^{\circ} \mathrm{C},(A)$ in the $M D$ and $(B)$ in the TD 

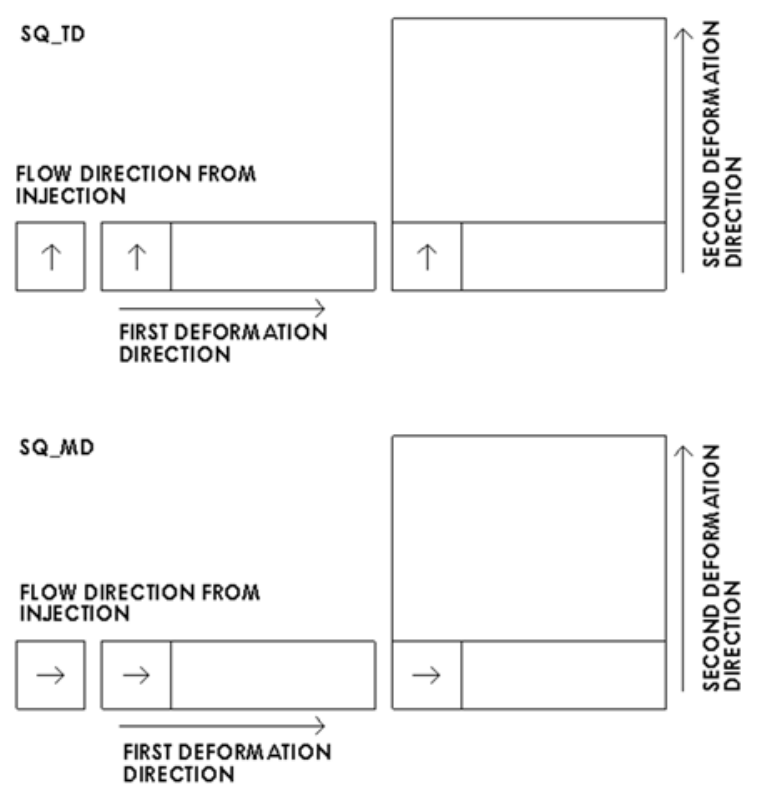

Figure 6 - Sample orientation relative to deformation direction during CW and SQ.

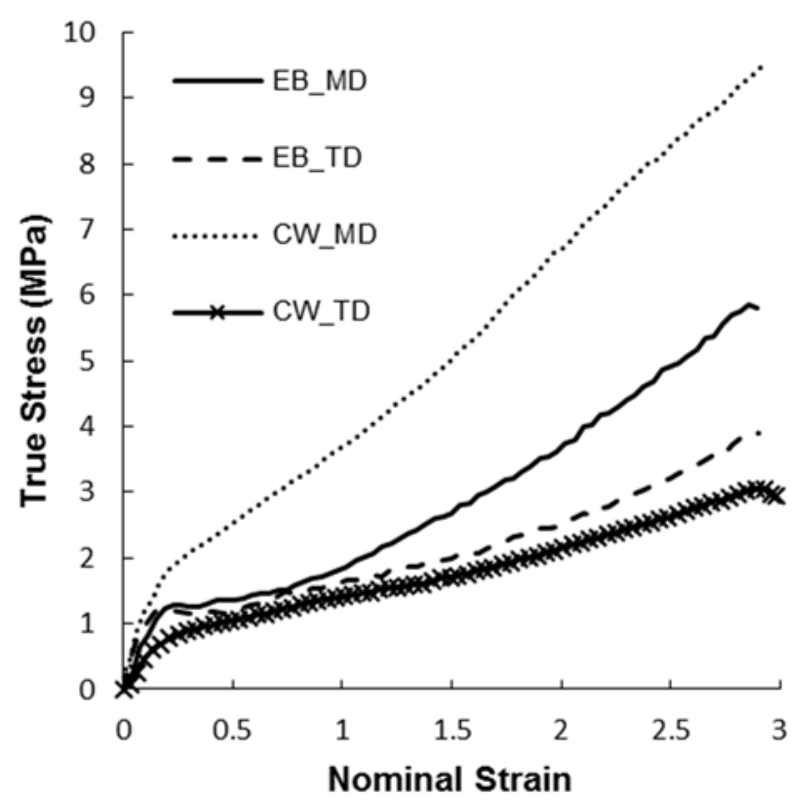

Figure 7 - Comparison of deformation modes, at $128^{\circ} \mathrm{C}$, at strain-rate of $4 \mathrm{~s}^{-1}$ 


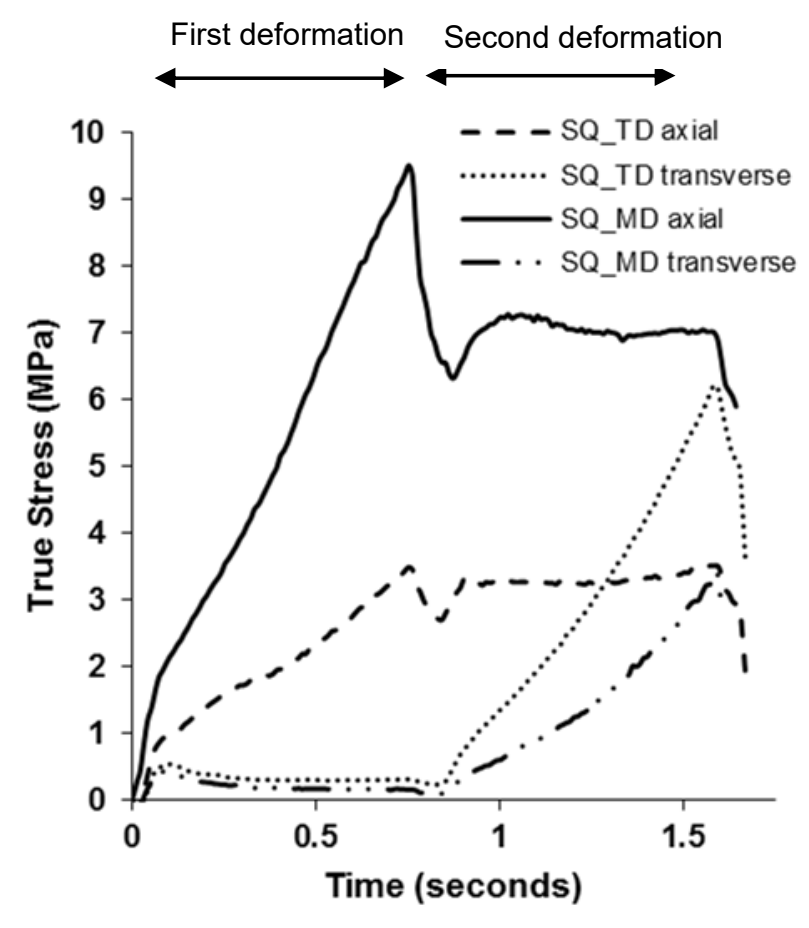

Figure 8 - Comparison of sample orientation during SQ deformation at $128^{\circ} \mathrm{C}$ and strain-rate $4 \mathrm{~s}^{-1}$. SQ_TD and SQ_MD refer to sample orientation specified in Figure 6, axial and transverse refer to the deformation direction. 
(A)

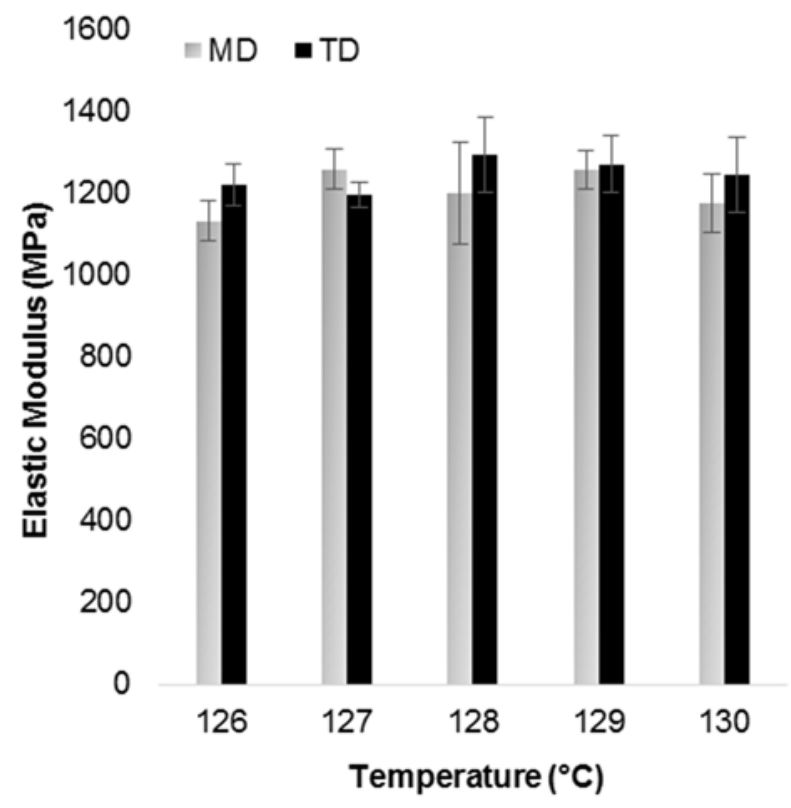

(B)

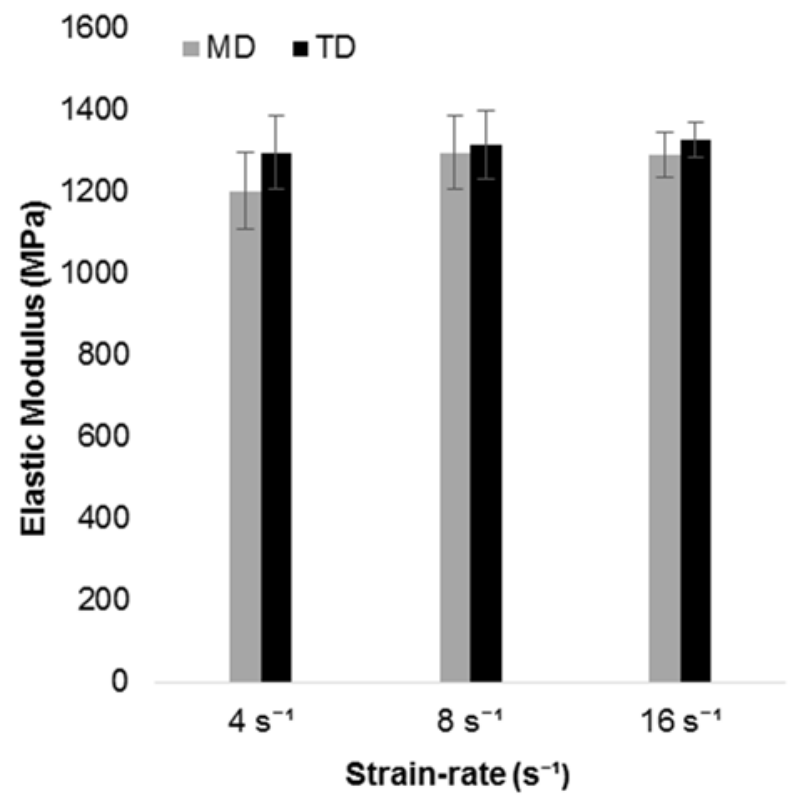

Figure 9 - The effect of forming temperature $(A)$ and strain-rate $(B)$ on the Young's Modulus of the sample post deformation at $128^{\circ} \mathrm{C}$ and strain-rate $4 \mathrm{~s}^{-1}$, determined via tensile testing at room temperature. 


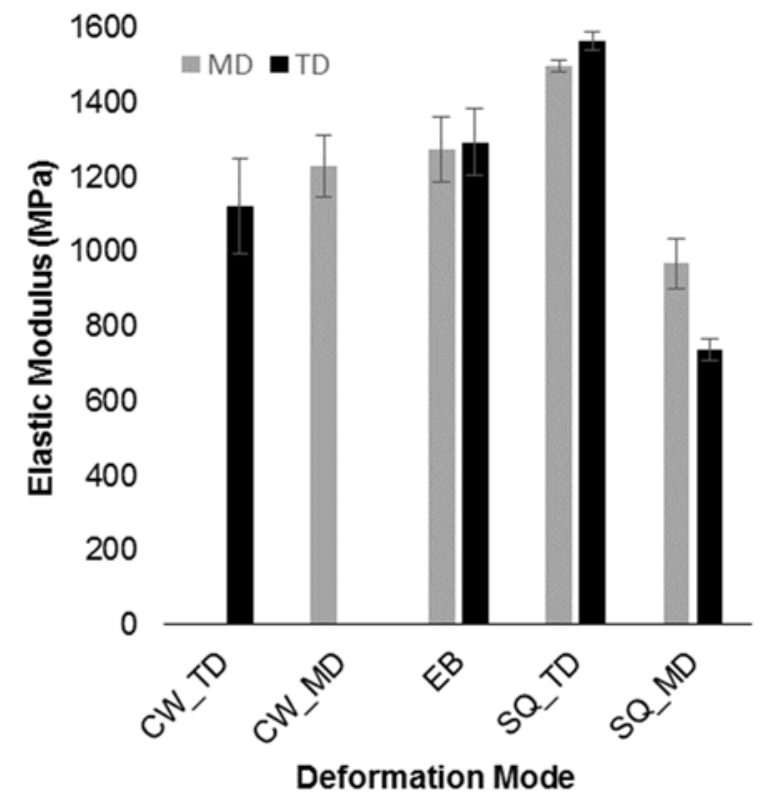

Figure 10 - The effect of deformation mode on the Young's Modulus of the sample post deformation at $128^{\circ} \mathrm{C}$ and strain-rate $4 \mathrm{~s}^{-1}$, determined via tensile testing at room temperature. 